\title{
FOOD ENRICHMENT WITH OMEGA-3 FATTY ACIDS
}

\author{
C. Jacobsen, N.S. Nielsen, A. Frisenfeldt Horn and A-D. Moltke Sørensen (Eds.)
}

Woodhead Publishing, Cambridge, June 2013, Series in Food Science, Technology and Nutrition No. 252, ISBN 978-0-85709-428-5 (print), ISBN-978-0-85709-886-3 (online), 426 pages

The book consists of four parts. Part I draws the background to omega-3 food enrichment: nutritional benefits, sources of omega-3 fatty acids are summarised, including future trends.

Part II deals with stabilisation of fish oils and foods enriched with omega-3 fatty acids. The impact of technological steps (extraction, refining and concentration) on stability of fish oils, stabilisation of omega-3 fatty acids and enriched foods with the help of antioxidants, emulsifiers, spray drying and encapsulation are also discussed. The analysis of omega- 3 fatty acids in foods and supplements is also described, including gas-liquid chromatographic determination, derivatisation, one-step methods combining extraction, digestion and derivatisation. Alternative analytical methods and future trends are treated as well.

Part III is devoted to food enrichment with omega-3 fatty acids in different ways, by modification of animal diets for enrichment of dairy and meat products with omega-3 fatty acids; enrichment of egg, meat products and baked goods. Emulsified foods and infant formulas are also supplemented. The sensory characteristics of infant formulas are also important.

Part IV shows new directions, for example algal oils as a source of omega-3 fatty acids. The closing part deals with labelling and claims in foods containing omega- 3 fatty acids. The practice of different continents (Europe, North America, Asia, Australia) is described, and the implications for the global food industry are treated.

Food enrichment with omega-3 fatty acids is a standard reference for professionals in the functional foods industry involved with research, development and quality assessment and for researchers in academia interested in food lipids, oxidation and functional foods.

M. Tóth-MARKuS 